\title{
CHILDREN WITH DOWN'S SYNDROME \\ IN LANCASTER, KENDAL \\ AND SOUTH LAKES
}

\author{
Sue Brown, Consultant; Ram Gobburu, SSHO; Paediatrics \\ Royal Lancaster Infirmary
}

\section{BACKGROUND}

Children with Down's syndrome are mainly well, with their main needs being educational and social, but they are at risk of certain conditions and do warrant regular medical review.

In light of recommendations from the Down's syndrome Medical Interest Group ${ }^{(1)}$ on medical follow-up of children with Down's syndrome, a form was designed for use in community clinics to act as an aide memoire (see appendix).

Versions of this form are now being used in Lancaster, Kendal and South Lakes. To aid audit, it is updated at the annual clinic visit and is photocopied to the office at Longlands, where the data are entered onto a spreadsheet database in Excel.

\section{AUDIT OF DOWN'S SYNDROME MANAGEMENT 2004}

To audit the management of children with Down's syndrome this database was checked and up-to-date information sought as necessary. The PCIS database was searched for children with Down's syndrome and colleagues were asked for information on any other children known to them.

\section{RESULTS}

Thirty-two children with Down's syndrome were identified.

\begin{tabular}{|l|c|c|}
\hline \multicolumn{2}{|l|}{ Children with Down's syndrome } \\
\hline & Lancaster & South Lakes \\
\hline Boys & 14 & 5 \\
\hline Girls & 9 & 4 \\
\hline Total & 23 & 9 \\
\hline Age of children & 6 & 3 \\
\hline Age 0-4 & 5 & 3 \\
\hline $5-8$ & 5 & 1 \\
\hline $9-12$ & 2 & 0 \\
\hline $13-16$ & 4 & 2 \\
\hline $17-20$ &
\end{tabular}

Frequency of contact

Children should be seen annually and we would expect all children to be seen within 24 months of their last appointment. As this review was carried out in the spring of 2004 , all children should have been seen in 2002, 03 or 04 .

In Lancaster $91 \%$ of children were seen during those years (one family has opted out of follow-up). In South Lakes the figure was $100 \%$.

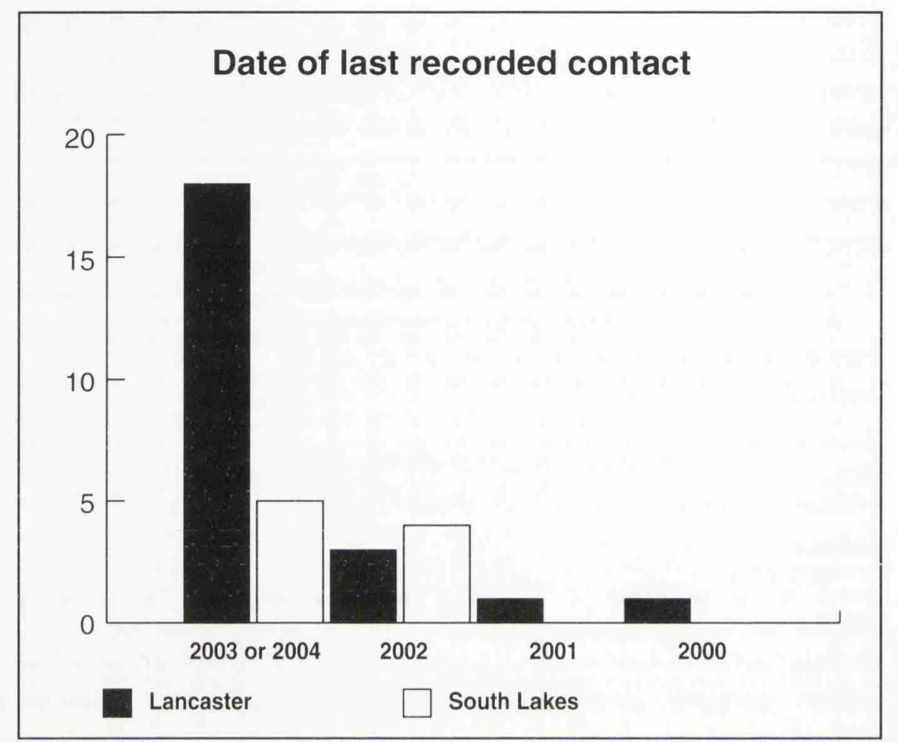

As a result of the audit we have identified failures in the system and triggered follow-up on those who were overdue.

\section{Recording of information}

\begin{tabular}{|l|c|c|c|}
\hline Information not recorded & \multicolumn{3}{|l|}{} \\
\hline & Lancaster & South Lakes & Total \\
\hline Hearing test & 1 & 0 & 1 \\
\hline Vision check & 1 & 0 & 1 \\
\hline Echocardiogram & 1 & 0 & 1 \\
\hline Thyroid function & 0 & 0 & 0 \\
\hline
\end{tabular}

Problems identified

\begin{tabular}{|l|c|c|c|}
\hline \multicolumn{4}{|c|}{ Problems identified in 31 children with Down's syndrome } \\
\hline Problem & Lancaster & South Lakes & Total \\
\hline Hearing impairment & 14 & 4 & 18 \\
\hline Visual problem & 12 & 4 & 16 \\
\hline Heart & 16 & 5 & 21 \\
\hline Needing thyroxine & 1 & 0 & 1 \\
\hline Behaviour & 6 & 2 & 8 \\
\hline
\end{tabular}

All the children had received a neonatal screen of hearing and most had follow-up audiology recorded. In one child in Lancaster hearing testing is not recorded on the database. There was a high incidence of hearing impairment, often due to glue ear.

\section{Schooling}

This was not consistently recorded on the database but 10 children (three from South Lakes) are recorded as attending special school. 


\section{CONCLUSIONS}

The database has made the audit rather easier but there were still children not on the database. As a result of this audit we have discovered that one or two young children with Down's syndrome were being followed up entirely within the hospital clinics and were not yet known in the community.

The audit has been useful in identifying children needing follow-up.

Follow-up has improved since the database was set up but we are not reaching our standards.
The high rate of abnormal findings reinforces the need for these children to have regular and thorough review. Once these children leave school their follow-up is left with their GP as there is no equivalent of community paediatricians for adult patients.

\section{REFERENCES}

1 Basic medical surveillance essentials for people with Down's syndrome. Recommendations of the Down's syndrome Medical Interest Group 2000 onwards. www.dsmig.org.uk

\section{APPENDIX}

DOWN'S SYNDROME - MEDICAL SURVEILLANCE

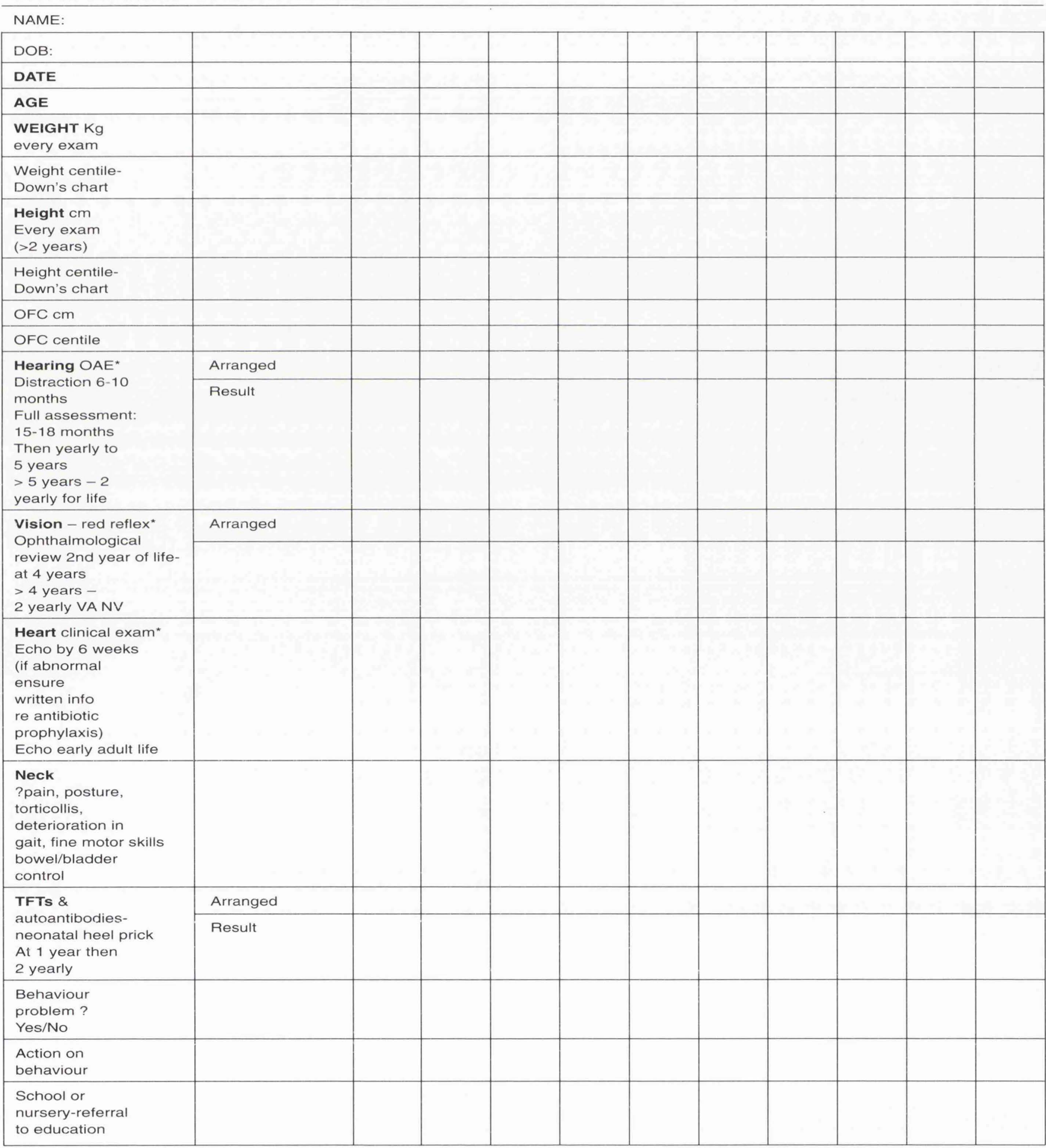

